\title{
MICROMOTION OF CEMENTED AND UNCEMENTED FEMORAL COMPONENTS
}

\author{
DENNIS W. BURKE, DANIEL O. O'CONNOR, EDWARD B. ZALENSKI, \\ MURALI JASTY, WILLIAM H. HARRIS
}

From Massachusetts General Hospital and Harvard Medical School

\begin{abstract}
We evaluated the initial stability of cemented and uncemented femoral components within the femoral canals of cadaver femurs during simulated single limb stance and stair climbing.

Both types were very stable in simulated single limb stance (maximum micromotion of $42 \mu \mathrm{m}$ for cemented and $30 \mu \mathrm{m}$ for uncemented components). However, in simulated stair climbing, the cemented components were much more stable than the uncemented components $(76 \mu \mathrm{m}$ as against $280 \mu \mathrm{m})$. There was also greater variation in the stability of uncemented components in simulated stair climbing, with two of the seven components moving $200 \mu \mathrm{m}$ or more. Future implant designs should aim to improve the initial stability of cementless femoral components under torsional loads; this should improve the chances of bony ingrowth.
\end{abstract}

Uncemented porous-coated total hip prostheses were introduced recently in the hope of increasing the longterm success rate of hip replacement in younger and more active patients (Engh 1983; Callaghan, Dysart and Savory 1988). Biological fixation by bone ingrowth into the surface pores is thought to provide durable and longlasting fixation (Galante et al 1971; Pilliar et al 1981; Harris and Jasty 1985).

Failure of total hip replacements may arise from excessive motion at the prosthesis-bone or cement-bone interface under weight-bearing loads. Minimising the micromotion of the uncemented prosthetic components is a key requirement for obtaining bone ingrowth (Pilliar et al 1981). If the initial movement is excessive, bone ingrowth into the porous surface will not occur.

Few experimental studies are available on implant micromotion, largely due to difficulty of simulating loads in vitro, and the problems of detecting minute movements. In many of the early studies, the femoral load imposed by the abductor muscles was not included, and the mechanical transducers had inadequate resolution, the lower limits being in the order of millimetres

D. W. Burke, MD

D. O. O'Connor, AS

E. B. Zalenski, AS

M. Jasty, MD

W. H. Harris, MD, Chief, Hip and Implant Surgery Unit

Orthopaedic Biomechanics Laboratories, Massachusetts General Hospital, Boston, Massachusetts 02114, USA.

Correspondence should be sent to Dr W. H. Harris.

(C) 1991 British Editorial Society of Bone and Joint Surgery 0301-620X/91/1058 \$2.00

J Bone Joint Surg [Br] 1991 ; 73-B :33-7.
(Charnley and Kettlewell 1965; McLeish and Charnley 1970; Oh and Harris 1978; Walker et al 1987).

Of even greater importance in evaluating the stability of the femoral prostheses are the effects of torsional forces that occur during activities such as climbing stairs; these have not been investigated in detail. Recent data from studies using instrumented hip prostheses show that some of the highest hip contact forces and joint reaction forces occur when climbing stairs or getting out of a chair (Hodge et al 1986; Davy et al 1988). Studies of fractured prosthetic stems show that failure of the implant almost always starts on the anterolateral corner as a result of torsional loads (Charnley 1975; Galante, Rostoker and Doyle 1975; Wroblewski 1982). Stereoroentgenographic studies of femoral component migration show that the femoral components usually migrate into retroversion as a result of posteriorly directed torsional moments (Nistor et al 1987).

We have measured the micromotion of cemented and uncemented femoral components under both simulated stance and stair-climbing loads in cadaver femora.

\section{MATERIALS AND METHODS}

Seven adult cadaveric femora were obtained from subjects who were free of musculoskeletal disease at the time of their death. All soft tissues were removed from the femora and anteroposterior and lateral contact radiographs were obtained at known magnification. Cementless and then cemented arthroplasties were carried out sequentially in each femur, which was loaded in stance and stair-climbing positions at each stage. The 
micromotion between the prosthesis and the bone was measured using sensitive displacement transducers.

Stance and stair-climbing loads. The loading apparatus to simulate single limb stance is shown in Figure 1. A simulated pelvis allows application of a load acting at the centre of gravity; woven nylon straps simulate the abductor muscles, and the knee is represented by a nonconstrained knife-edge joint to eliminate unphysiological bending moments. The loading characteristics, such as moment arm lengths, inclination of the femur, and abductor origin and insertion points were obtained from the data published by McLeish and Charnley (1970) for single leg stance. Points of muscle insertion, hip centre, load application and bony angulation were held constant for all specimens. Both the joint reaction forces and abductor forces were monitored using load cells to verify the reliability of the loading parameters in each test situation.

To obtain information on the position of the hip in stair climbing, biplanar radiographs of three volunteers were taken while they were climbing a stair. The radiographs were analysed in both coronal and sagittal planes to determine the centre of gravity, the centre of the hip, and the position and orientation of the skeletal segments. To determine the position of the abductor and extensor muscle groups in stair climbing, we carried out a separate study of the muscle mass distribution of a volunteer climbing a stair, while computer tomographs of the hip were taken using a scanner with a vertical gantry (Stracher, Jasty and Harris 1988). These data were reconstructed in three dimensions. The moment arms of the muscles were compared with those reported by other investigators (Nistor et al 1987) and were found to be similar.

The loading apparatus used to apply stair-climbing loads contained a simulated pelvis which could be oriented in three dimensions (Fig. 2). An acetabular component was fixed to the simulated pelvis with a cylindrical beam, instrumented with a three-dimensional load-sensor to measure the joint reactive force. The abductor and extensor muscle groups were simulated using woven nylon straps attached to the femur and the pelvis. Based on radiographic and CT data, the position and orientation of the bones and muscles were reproduced. A curved muscle path rather than a straight line was chosen for the gluteus maximus, as determined from the CT data. The muscle path was shaped by buttressing the extensor muscle strap with a foam pad. Both the abductor and extensor muscles were instrumented with load cells to quantify their forces.

Micromotion sensing apparatus. Micromotion between prosthesis and bone was measured using electrical displacement transducers (extensometers, MTS Corporation, Minneapolis, USA) attached by special fixtures (Fig. 3). A cylindrical metal pin was press-fitted into the femoral component through clearance holes made in the anterior femoral cortex. A hollow metal cylinder was

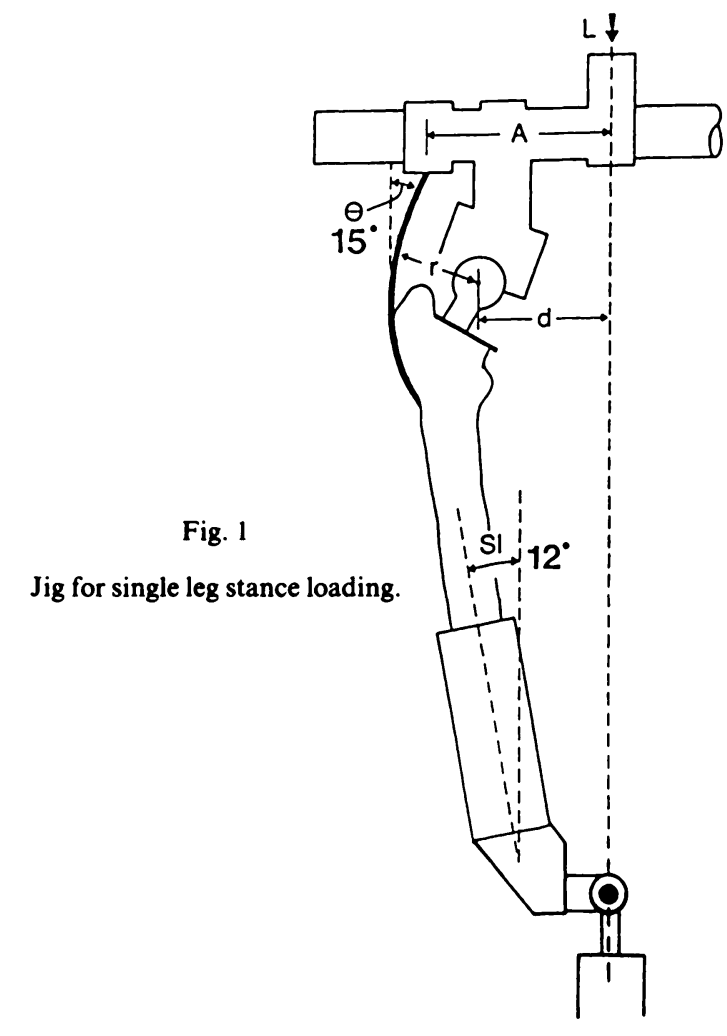

Table I. Micromotion in $\mu \mathrm{m}$ of cemented and uncemented prostheses under $115 \mathrm{lb}(52 \mathrm{~kg})$ load

\begin{tabular}{|c|c|c|c|c|c|c|c|c|}
\hline \multirow[b]{3}{*}{ Femur } & \multicolumn{4}{|c|}{ Cementless } & \multicolumn{4}{|c|}{ Cemented } \\
\hline & \multicolumn{2}{|l|}{ Axial } & \multicolumn{2}{|c|}{$\begin{array}{l}\text { Transverse } \\
\text { (rotatory) }\end{array}$} & \multicolumn{2}{|l|}{ Axial } & \multicolumn{2}{|c|}{$\begin{array}{l}\text { Transverse } \\
\text { (rotatory) }\end{array}$} \\
\hline & $\mathbf{S L S}^{*}$ & $\mathrm{SC}+$ & SLS & SC & SLS & SC & SLS & SC \\
\hline 1 & 14.0 & 12.4 & 1.6 & 15.2 & 42.0 & 18.0 & 12.6 & 55.0 \\
\hline 2 & 6.6 & 3.4 & 5.6 & 14.0 & 18.0 & 6.0 & 6.6 & 76.0 \\
\hline 3 & 4.4 & 7.5 & 4.8 & 13.0 & 2.2 & 1.4 & 11.4 & 2.0 \\
\hline 4 & 30.0 & 14.0 & 2.4 & 200.0 & 1.6 & 8.0 & 1.4 & 10.0 \\
\hline 5 & 7.2 & 20.02 & 7.8 & 106.0 & 2.0 & 1.6 & 0.7 & 21.0 \\
\hline 6 & 1.6 & 2.6 & 1.4 & 280.0 & 9.0 & 2.6 & 0.8 & 14.6 \\
\hline 7 & 8.8 & 11.0 & 5.4 & 93.2 & 3.3 & 2.3 & 0.8 & 5.0 \\
\hline Mean & 10.37 & 10.13 & 7.0 & 103.1 & 11.16 & 5.70 & 4.90 & 26.23 \\
\hline SD & 9.47 & 6.15 & 9.34 & 103.7 & 14.83 & 5.96 & 5.29 & 28.19 \\
\hline
\end{tabular}

*SLS, single leg stance

$+\mathrm{SC}$, stair climbing

then attached to the clearance hole in the bone using epoxy resin, so that the outer cylinder surrounded and was concentric with the central pin. An electrical displacement transducer was attached to the central pin and to the outer cylinder using special platforms. Motion was measured between the pin attached to the prosthesis and the outer cylinder attached to bone. Using the 

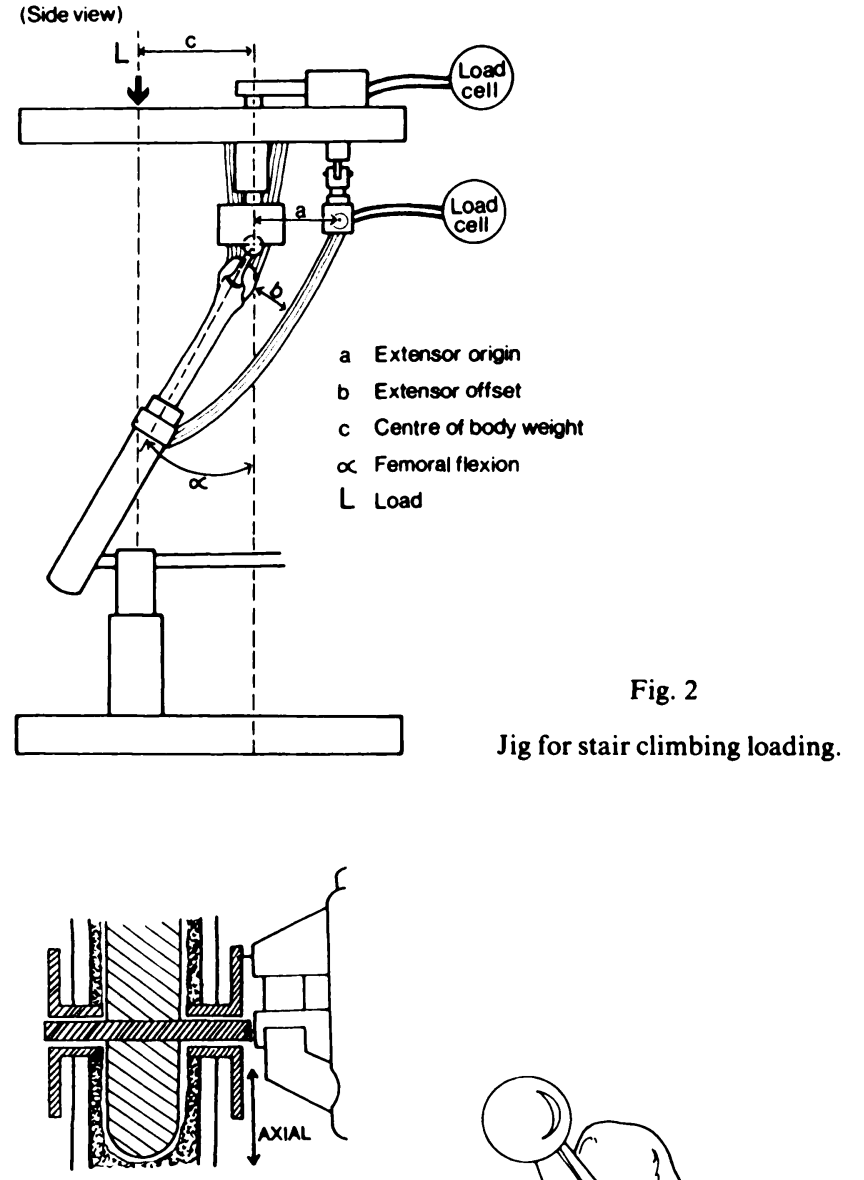

MEASURING SUBSIDENCE

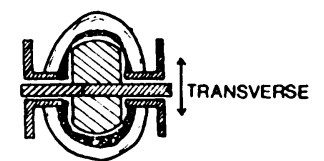

MEASURING ROTATION

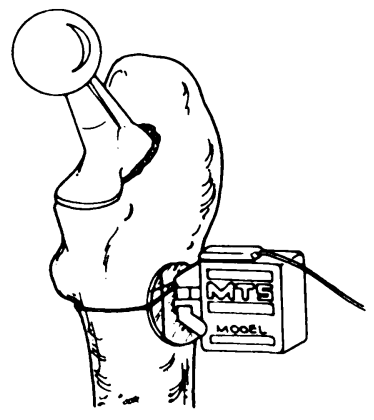

Fig. 3

Apparatus for measuring micromotion.

displacement transducer in either a vertical or a horizontal position, either axial or transverse motion could be recorded.

The pin was attached to the prosthesis $3 \mathrm{~cm}$ distal to the collar (Fig. 3). This location was chosen since movement adjacent to the proximal porous zone of the prosthesis was thought to be detrimental to bone ingrowth. Measurements of the motion both at the anterior and posterior aspects of the femur were made in three cemented and three uncemented components. Movement of the pins relative to the anterior and posterior femoral cortices, allowed the detection of the axial motion, translatory motion and rotatory motion of the prostheses.

Sequence of the experiments. First, a cementless femoral component was inserted in each bone by an experienced orthopaedic surgeon using standard surgical techniques and a straight-stemmed, collared femoral component (HGP, Zimmer Inc, Warsaw, USA). The largest femoral component that the femoral canal would accept was used.

The femur was then instrumented with the micromotion sensing device, fastened to the loading jigs and mounted onto the MTS servohydraulic materials test system (MTS Corporation, Minneapolis, USA). A $5 \mathrm{lb}$ $(2.3 \mathrm{~kg})$ preload was applied to the femur and the extensometers were reset to zero. The stance and then the stair-climbing loads were applied sequentially using the two different loading jigs. The same spinal load of $445 \mathrm{~N}$, simulating the weight of a $115 \mathrm{lb}(52 \mathrm{~kg})$ subject was applied in each instance. This relatively small load was chosen to minimise the chance of causing a fracture during the test procedure. Outputs from the extensometers were recorded at full load. The load was then removed and the output of the extensometers was again recorded to determine if any permanent displacement had occurred. All loadings were repeated three times to verify the reproducibility of the data. Joint reaction forces and muscle forces were also recorded to monitor the reproducibility of the loading.

The cementless component was then removed and a cemented femoral component (THR pre-coat, Zimmer Inc, Warsaw, USA) was inserted using centrifuged Simplex $\mathrm{P}$ bone cement, with a medullary plug of bone cement and pressurisation. The loading sequence was then repeated and the micromotion measured.

\section{RESULTS}

Single leg stance. Both the cemented and the cementless femoral components used in this study showed remarkable stability under loads simulating single leg stance (Table I). Mean axial micromotion of the cemented component was $11 \mu \mathrm{m}( \pm 15)$ and of the cementless component $10 \mu \mathrm{m}( \pm 9)$. The average transverse (or rotatory) micromotion in simulated stance was even lower, at $6 \mu \mathrm{m}( \pm 6)$ for cemented stems and $7 \mu \mathrm{m} \pm 9$ ) for cementless. The maximum micromotion recorded was $42 \mu \mathrm{m}$ for the cemented components and $30 \mu \mathrm{m}$ for the uncemented components.

Stair climbing. During stair climbing, however, there was substantially more micromotion of the uncemented than the cemented prostheses (Table I). The mean transverse (or rotatory) micromotion of the uncemented prostheses was $103 \mu \mathrm{m}( \pm 104)$ compared to $26 \mu \mathrm{m}( \pm 28)$ for cemented stems, a significant difference $(p<0.05)$. In cemented stems, the range was from $2 \mu \mathrm{m}$ to $76 \mu \mathrm{m}$ while, in contrast, the cementless components showed rotatory micromotion from $13 \mu \mathrm{m}$ to $280 \mu \mathrm{m}$. In two femora, rotatory micromotion of the prosthesis was greater than $200 \mu \mathrm{m}$ and in a third, it was between $100 \mu \mathrm{m}$ and $200 \mu \mathrm{m}$. 
Relatively little micromotion was observed in the axial direction during stair climbing with either cemented or cementless prostheses: the average anterior axial micromotion being $10 \mu \mathrm{m}( \pm 6)$ for the uncemented prostheses and $6 \mu \mathrm{m}( \pm 6)$ for the cemented prostheses. There was no significant difference between the axial micromotion in simulated stair climbing compared to simulated stance in either cemented or uncemented prostheses .

Comparison of the micromotion at the anterior and posterior surfaces in selected femora showed that motion of both cemented and uncemented prostheses in stair climbing was mostly rotational, with the prosthesis moving into retroversion. In simulated stance, the anterior and posterior transverse micromotion was usually in the same direction, indicating a shift into varus.

The micromotion of the cemented femoral components increased linearly with increasing load during both simulated stance and stair climbing (Fig. 4). The micromotion of the uncemented femoral components, however, showed a nonlinear relationship to increasing loads. At large loads, the micromotion increased more rapidly with incrementally larger loads. However, irreversible movement did not occur with either the cemented or uncemented components during stance or stair climbing in these experiments at these loads.

\section{DISCUSSION}

Excessive movement at the prosthesis-bone interface was an original impetus for using cement in total hip arthroplasty. Charnley and Kettlewell (1965) demonstrated that the addition of acrylic cement around the prosthetic components reduced the micromotion of the cementless implants used at that time by an order of magnitude. Many advances in the design of uncemented prostheses have since been made in order to enhance prosthetic stability (Engh 1983; Walker et al 1987).

We have shown that the micromotion of both the cemented and cementless femoral components used in this study is very small under simulated stance. This is in marked contrast to the much larger micromotion of the cementless components compared to the cemented components in simulated stance observed in previous studies (Charnley and Kettlewell 1965; Markolf, Amstutz and Hirschowitz 1980; Walker et al 1987). The presence of the collar on the prosthesis, the filling of the isthmus by the prosthesis, and tight press-fit in the femoral canal may have contributed to initial stability of uncemented femoral components under loads simulating single limb stance.

During simulated stair climbing, however, the substantial torsional loads placed on the components led to marked increases in the micromotion of uncemented prostheses and smaller (although significant) increases in the micromotion of cemented components. The unce-

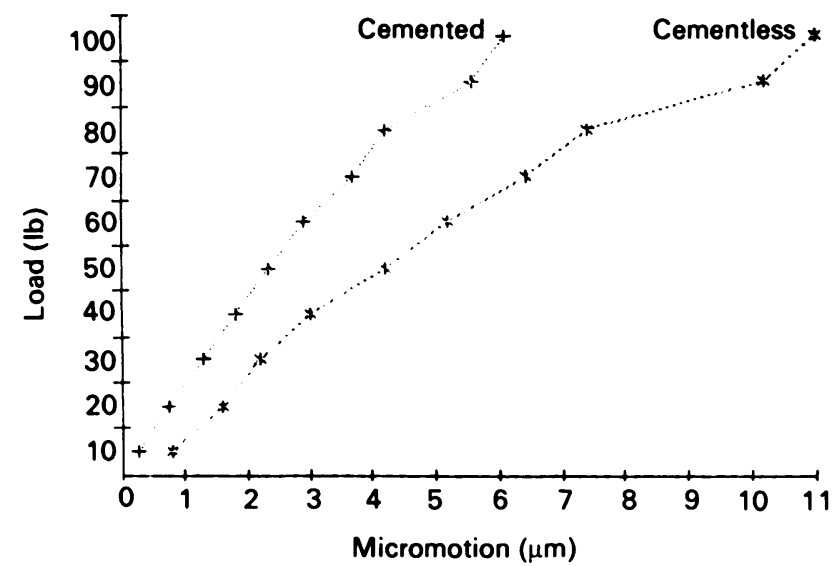

Fig. 4

Relationship between axial micromotion and the applied load.

mented components showed the largest micromotion (four times as much as the cemented) and were, therefore, the least stable during stair climbing.

Although the extent of micromotion which is detrimental to the long-term stability of cementless prosthetic components is not known, the large micromotions found in this study could interfere with bone ingrowth since most prostheses currently have a mean pore size of $200 \mu \mathrm{m}$ to $300 \mu \mathrm{m}$. Motion at the cementbone interface can lead to fragmentation of the cement, generate particulate debris of methylmethacrylate and may lead to bone lysis around the prosthetic components (Lewis et al 1985; Goldring et al 1986).

Preliminary reports of cementless porous-coated hip prostheses have shown a high incidence of thigh pain, femoral component subsidence and breakdown of the porous coatings after short follow-up periods (Engh 1983; Callaghan et al 1988). Studies of porous-coated components retrieved from patients suggest that only a small amount of bone ingrowth into the porous surface occurs (Cook, Thomas and Haddad 1988). Future designs of uncemented femoral components should aim at providing both rotatory stability and axial stability to improve anchorage by bone ingrowth.

Concern over rotatory instability of uncemented femoral components has also led us to modify the postoperative regimen of patients currently undergoing total hip arthroplasty without cement. We recommend partial weight-bearing with crutches for three months and advise patients not to climb stairs with the operated leg nor to get out of chairs without using the arms. If possible, we avoid performing a second contralateral uncemented total hip replacement within three months of the first.

The spinal loads used in the study were relatively small, representing the hip loads of a person weighing only $115 \mathrm{lb}(52 \mathrm{~kg})$. We chose these low loads because of the experimental difficulty in applying larger loads to the 
cadaver femur, and the potential for fracturing the femur or the greater trochanter. Larger forces imposed by heavier individuals would probably result in greater movement of any implant.

We acknowledge partial support by grants from Zimmer Inc, Warsaw, Indiana, USA, and the William $\mathrm{H}$. Harris Foundation.

One or more of the authors have received or will receive benefits for personal or professional use from a commercial party related directly or indirectly to the subject of this article. In addition benefits have also been or will be directed to a research fund, foundation, educational institution, or other non-profit institution with which one or more of the authors is associated.

\section{REFERENCES}

Callaghan JJ, Dysart SH, Savory CG. The uncemented porous-coated anatomic total hip replacement: two-year results of a prosthetic consecutive series. J Bone Joint Surg [ Am] 1988; 70-A:337-46.

Charnley J. Fracture of femoral prostheses in total hip replacement : a clinical study. Clin Orthop 1975; $111: 105-20$.

Charnley J, Kettlewell J. The elimination of slip between prosthesis and femur. J Bone Joint Surg [Br] 1965; 47-B:56-60.

Cook SD, Thomas KA, Haddad RJ Jr. Histologic analysis of retrieved human porous-coated total joint components. Clin Orthop 1988; 234:90-101.

Davy DT, Kotzar GM, Brown RH, et al. Telemetric force measurements across the hip after total hip arthroplasty. J Bone Joint Surg [ Am] $1988 ; 70-A: 45-50$.

Engh CA. Hip arthroplasty with a Moore prosthesis with porous coating: a five-year study. Clin Orthop 1983; 176:52-66.

Galante J, Rostoker W, Lueck R, Ray RD. Sintered fiber metal composites as a basis for attachment of implants to bone. $J$ Bone Joint Surg [Am] 1971; 53-A :101-14.

Galante JO, Rostoker W, Doyle JM. Failed femoral stems in total hip prostheses. J Bone Joint Surg [Am] 1975; 57-A :230-6.
Goldring SR, Jasty M, Roelke MS, Rourke CM, Bringhurst FR, Harris WH. Formation of a synovial-like membrane at the bone-cement interface: its role in bone resorption and implant loosening after total hip replacement. Arthritis Rheum 1986; 29:836-42.

Harris WH, Jasty M. Bone ingrowth into porous coated canine acetabular replacements: the effect of pore size, apposition, and dislocation. In: The Hip Procs of the 13th meeting of the Hip Society 1985. St Louis: CV Mosby Co, 1985; 214-34.

Hodge WA, Fijan RS, Carlson KL, Burgess RG, Harris WH, Mann RW. Contact pressures in the human hip joint measured in vivo. Proc Natl Acad Sci USA 1986; 83:2879-83.

Lewis JL, Nicola T, Keer LM, Clech JP, Steege JW, Wixson RL. Failure processes at the cancellous bone-PMMA interface. Trans Orthop Res Soc 1985; 10:144.

Markolf KL, Amstutz HC, Hirschowitz DL. The effect of calcar contact on femoral component micromovement: a mechanical study. $J$ Bone Joint Surg [Am] 1980; 62-A:1315-23.

McLeish RD, Charnley J. Abduction forces in the one-legged stance. $J$ Biomech 1970; 3:191-209.

Nistor L, Blaha JD, Kjellstrom U, Selvik G. In vivo measurement of relative motion between an uncemented femoral total hip component and the femur by roentgen stereophotogrammetry. Trans Orthop Res Soc 1987; 12:485.

Oh I, Harris WH. Proximal strain distribution in the loaded femur: an in vitro comparison of the distributions in the intact femur and after insertion of different hip-replacement femoral components. $J$ Bone Joint Surg [ Am] 1978; 60-A :75-85.

Pilliar RM, Cameron HU, Welsh RP, Binnington AG. Radiographic and morphologic studies of load-bearing porous-surfaced structured implants. Clin Orthop 1981; 156:249-57.

Stracher MA, Jasty M, Harris WH. A multi-dimensional study of the human hip during stair climbing. Trans Orthop Res Soc 1988; 12:545.

Walker PS, Schneeweis, Murphy S, Nelson P. Strain and micromotions of press-fit femoral stem prostheses. J Biomech 1987; 20:693-702.

Wroblewski BM. Fractured stem in total hip replacement: a clinical review of 120 cases. Acta Orthop Scand 1982; 53:279-84. 